\title{
Are you really cursing? Neural processing of taboo words in native and foreign language
}

Simone Sulpizio ${ }^{1}$, Michelle Toti $^{1}$, Nicola Del Maschio ${ }^{1},{\text { Albert } \text { Costa }^{2,3} \text {, Davide Fedeli }}^{1}$, Remo Job $^{4}, \&$ Jubin Abutalebi ${ }^{1}$

${ }^{1}$ Centre for Neurolinguistics and Psycholinguistics, Vita-Salute San Raffaele University and San Raffaele Scientific Institute, Milan, Italy

${ }^{2}$ Center for Brain and Cognition (CBC), Universitat Pompeu Fabra, Barcelona, Spain

${ }^{3}$ Institució Catalana de Recerca i Estudis Avançats (ICREA), Barcelona, Spain

${ }^{4}$ Department of Psychology and Cognitive Science, University of Trento, Trento, Italy

Corresponding author:

Prof. Jubin Abutalebi

Vita-Salute San Raffaele University,

Via Olgettina, 58, 20132 Milan, Italy.

Email: abutalebi.jubin@hsr.it 


\begin{abstract}
The use of socially opprobrious words (taboo words) is a cross-cultural phenomenon occurring between individuals from almost all social extractions. The neurocognitive correlates of using taboo words in the native language (L1) as compared to their use in a second (L2) language are largely unknown. We used fMRI to investigate the processing of taboo and non-taboo stimuli in monolinguals (Experiment 1) and highly proficient bilinguals (Experiment 2) engaged in lexical decision tasks. We report that for L1 socio-pragmatic knowledge is automatically conveyed and taboo words are processed with less effort than non-taboo words. For L2 the processing of taboo words is more effortful and engages additional structures (anterior cingulate cortex, insula) involved in social-norm representation and evaluation. Our results contribute to understand the interface between language and social-norm processing indicating that lexical processing is affected by socio-pragmatic knowledge, but only when the speaker has a contextual use of the language.
\end{abstract}

Keywords: taboo words; fMRI; bilingualism; lexical decision 
Swearing - intended as the use of socially opprobrious words - is a unique linguistic behavior that has always characterized language communication, as attested by the most ancient written instances of swearing that date back to the era of Ramses III (1198-1166 B.C.; Ljung, 2011). Swear or taboo words are used cross-culturally and by people of all social extractions in order to obtain a variety of emotionally-connoted personal and interpersonal outcomes (Jay, 2009), with a relatively high frequency of occurrence (i.e., $\sim 0.5 \%$ of daily production, Mehl \& Pennebaker, 2003). Peculiarly, swear words also persist in severe aphasic patients when linguistic production is otherwise lost, suggesting that they might be represented and stored in different neural networks from non-taboo words (Van Lanker \& Cummings, 1999). Taboo words are able to codify promptly and directly relevant emotional content as well as social and interpersonal relationships. They are thus unique as they are: ubiquitous; multipurpose - i.e., the same word may have a negative, positive, or inconsequential emotional impact; persistent even in the presence of sever language dysfunction; socially salient, as they may signal relevant cues as to the interlocutors social status and/or in- and out-group membership; and a tool to intensify emotional communication (Jay, 2009). The use of this class of words is restricted and often the context of communication requires to suppress taboo words for institutional (e.g. a formal meeting) and/or individual (e.g. presence of children) reasons.

Despite their importance and frequency, taboo words have received very little attention in the cognitive neuroscience literature and their neural correlates are still largely unknown. Most of what we know on how taboo language is processed comes from sporadic behavioral and psychophysiological investigations, which have used taboo words as a special case of emotional stimuli and showed that, relative to emotionally-neutral words, visually presented taboo words are associated with superior recall in surprise memory tests (MacKay, Shafto, Taylor, Marian, Abrams,\& Dyer, 2004), enhanced attention (Anderson, 2005), heightened autonomic response (LaBar \& Phelps, 1998), and are harder to inhibit when presented as distractors in a picture-word interference task (Dhooge \& Hartsuiker, 2011). 
An interest for taboo language has recently developed in bilingualism research, mostly with the aim to test whether the emotion-language coupling is similarly tight in the speaker's first (L1) and second language (L2). Emotion-language coupling is often considered to be less efficient and automatic in L2 (Hayakawa, Costa, Foucart, \& Keysar, 2016; Hayakawa, Tannenbaum, Costa, Corey \& Keysar, 2017) and some studies suggested that auditory and visually presented taboo words elicit weaker automatic response in L2 than in L1 (e.g., Harris, Aycicegi, \& Gleason, 2003). Similarly, the use of a foreign language increases emotional distance, favoring cold-head over hot-emotional moral choices (Costa et al., 2014). On this issue, testing Chinese-English bilinguals in a lexical decision task, Chen and colleagues (2015) found that, in left middle occipital gyrus and left cerebellum, neural activation of processing emotional words varied in L1 and L2 - i.e., in L1 emotional words elicited weaker activation than neutral words in middle occipital gyrus and cerebellum; the authors argue that accessing to emotional information is easier and more automatized in L1 than in L2. However, other pieces of evidence suggest that the emotional-language coupling may depend on language proficiency: when the proficiency in L2 is high, taboo words elicit similar behavioral reactions in both L1 and L2 (e.g., Ferre, Fraga, Sanchez-Casas, \& Molero, 2010). In such a perspective, the impact of a foreign language on moral decision-making (i.e., a less emotional choice in L2) would be ascribed to a reduced access to social and moral knowledge, not to a dampening of emotions (Geipel, Hadjichistidis, \& Surian, 2015).

Taboo words thus represent a window into the interface between language and socio-pragmatic competence. To our knowledge, no neuroimaging study has directly investigated the processing of taboo words, neither in the speakers' native language nor in bilinguals' L2. The present study is intended to fill this gap by answering the following questions: To what extent are the neural correlates of taboo words and non-taboo words processing similar? Do the intensity of activation and the neuroanatomical loci associated with taboo words differ between L1 and L2, similarly to what happens with the emotional-language coupling? The answers to these issues will shed light on the neural 
organization and processing of this unique lexico-semantic category and, more interestingly, on the interface between language and social norm processing, along with whether such interface works similarly in the speaker's languages. Indeed, being able to perceive and produce socially appropriate linguistic acts is at the basis of communication, as linguistic ill-formed locutions may produce infelicitous, inappropriate, and/or impolite effects.

In the present study, we ran two functional Magnetic Resonance Imaging (fMRI) studies in which Italian monolinguals (Experiment 1) and high proficient Italian-English bilinguals (Experiment 2) were presented with taboo words and non-taboo words and asked to perform a lexical decision task. We used a multifaceted approach involving behavioral responses, univariate fMRI analyses comparing the intensity of the BOLD signal, and multivariate pattern analyses (MVPA) for the differentiation of activation patterns across multiple voxels possibly distributed in non-adjacent brain regions. To investigate the social appropriateness of taboo words without the confounding of their potential emotional connotation we equated taboo words and non-taboo words in terms of arousal and valence.

With regard to the brain regions expected to differentiate taboo words from non-taboo words, some hints to sketch our predictions come from studies investigating socio-pragmatic and moral competence, being taboo words socially inappropriate expressions. A recent meta-analysis points to the medial frontal gyri and the anterior cingulate as key regions for processing social norm representation, whereas dorsolateral prefrontal cortices, cingulate cortices and the insula are assumed to be the core regions for processing norm violation (Zinchenko \& Arsalidou, 2018). These regions are possibly sensitive to the social appropriateness of our stimuli. Moreover, since higher-level social knowledge processing has been shown to impact activity in lower-level visual regions such as the fusiform gyrus and the ventral visual cortices (e.g., Stolier \& Freeman, 2016), taboo words and non-taboo words might differentiate already during the early stages of word recognition involving occipito-temporal areas.

As for our second question, i.e., whether the intensity of activation and the neuroanatomical loci 
associated with taboo words differ in L1 and L2, two contrasting predictions can be proposed based on behavioral evidence in native and foreign language. If the use of the foreign language dampens the effect of processing a socially inappropriate content, then processing taboo words in L1 should activate a more extended network of brain areas or have stronger activation related to social processing than processing taboo words in L2. Instead, if socio-emotional processing is similarly engaged by native and foreign language in high proficient bilinguals, a similar pattern is expected for L1 and L2.

\section{Materials and Method}

\section{Participants.}

Participants comprised 22 high-proficient Italian-English bilinguals (13 females, MEAN age: 23.23, SD: 2.41) and 22 Italian monolinguals (12 females, $M E A N$ age: $23.5, S D: 3.58$ ). This sample size was determined on the basis of prior fMRI research on word processing and was similar to that used in previous studies in our lab that link fMRI signals to behavior (e.g., Abutalebi et al., 2012; Canini et al., 2016). Data from two monolingual participants were excluded (1 for excessive movements in the scan and 1 because self-declared to be a reader with dyslexia only after the end of the experiment) leaving 20 participants for the analyses. All participants were Italian-native speaker, right handed (according to the Edinburgh inventory, Oldfield, 1971; MEAN score: $0.8 S D=0.4$ ); the two groups were matched on educational and economic background (mean education (yrs): monolinguals 15.70 (SD: 1.78) vs. bilinguals $16.68(S D=1.61), \mathrm{p}>.06$; economic income (on 1-to-5 point scale: monolinguals 3.95 ( $S D$ : 1.14) vs. bilinguals $4.45(S D=0.85) \mathrm{p}>.06)$. All participants, recruited in the city of Milan and its hinterland, were physically healthy and free of neurological disease, head injury or psychiatric disorder. Both groups performed the on-line Cambridge test for adult learners (https://www.cambridgeenglish.org/it/test-your-english/adult-learners/), which consist in 25 questions testing grammatical and conversational knowledge. All bilinguals obtained a score of 23 or higher 
(which corresponds to a C2 proficiency level), whereas monolinguals obtained a score of 12 or lower (which corresponds to an A2 level or lower).

For the bilingual group, language proficiency was further assessed by using an L1-to-L2 translation task of 90 words (30 high-frequency, 30 medium-frequency, and 30 low-frequency words; see Abutalebi et al., 2012). Moreover, subjective measures of age of acquisition (AoA, in years), proficiency (as a 1-to-10 scale in writing and speaking proficiency), and exposure (measured as the amount of daily exposure to languages in areas including media, family, university, friends, job, and hobbies, see for detail Wartenburger et al., 2003) were collected for the second language. Bilinguals had an average accuracy of $85.30 \%(S D: 9.50 \%)$ in the translation task, started to acquire their second language early (AoA: $M E A N=6.36, S D=3.43$ ), were high proficient (Writing Level: $M E A N=8.54$, $S D=0.67$; Speaking Level: $M E A N=8.54, S D=0.73$ ), and highly exposed to their second language ( $>8$ hours per day). The study was approved by the University Vita-Salute San Raffaele Research Ethics Committee and was carried out in compliance with their guidelines.

\section{Stimuli.}

One set of Italian stimuli and one of English stimuli were used. The Italian set consisted of 35 taboo words selected from ITABÙ (Sulpizio, Vassallo, Job, \& Abutalebi, 2018) and 35 non-taboo words selected from the Italian adaptation of the Affective Norms for English Words (ANEW) (Montefinese et al., 2013); taboo words were socially-inappropriate words belonging to the domains of sexuality and insults, whereas non-taboo words were socially appropriate words belonging to different domains (for the list of stimuli, see Supplementary material). Taboo words and non-taboo words were matched on: Written frequency, length, orthographic neighborhood size, orthographic neighborhood frequency, orthographic Levenshtein distance, imageability, concreteness, familiarity, arousal, and valence (see Table 1, all ps >.1). Seventy pseudowords were created as fillers and matched with words on length (p 
$>$.1). Pseudowords were all phonotactically legal and did not resemble any real word.

Also the English set consisted of 35 taboo words (selected from Janschewitz, 2008) and 35 nontaboo words (selected from SUBTLEX-UK, Van Heuven, Mandera, Keuleers, \& Brysbaert, 2014), with taboo stimuli again belonging to the domains of sexuality and insults, and non-taboo stimuli belonging to different domains (for the list of stimuli, see Supplementary material). Approximately half of both taboo words and half of the non-taboo words were translation of the Italian stimuli. Taboo words and non-taboo words were matched on: Frequency, length, orthographic neighborhood size, orthographic neighborhood frequency, orthographic Levenshtein distance, arousal, and valence (see Table 1, all ps $>.07)^{1}$. Seventy filler pseudowords were created using Wuggy (Keuleers \& Brysbaert, 2010); they were phonotactically legal and matched with words on length $(\mathrm{p}>.5)$.

1 Measures of concreteness, imageability, and familiarity were not available for English taboo words. 
Table 1. Summary statistics: means (and standard deviations) for word stimuli used in the Italian and the English experiment.

\begin{tabular}{|l|l|l|l|l|}
\hline & \multicolumn{3}{|c|}{ Italian } & \multicolumn{2}{c|}{ English } \\
\hline & Non-taboo & Taboo & Non-taboo & Taboo \\
\hline Written Frequency & $\begin{array}{l}1853.74 \\
(3169.87)\end{array}$ & $\begin{array}{l}5937.62 \\
(12519.21)\end{array}$ & $\begin{array}{l}1836.91 \\
(2499.35)\end{array}$ & $\begin{array}{l}1868.88 \\
(2804.25)\end{array}$ \\
\hline Length & $\begin{array}{l}7.34 \\
(2.11)\end{array}$ & $\begin{array}{l}6.60 \\
(1.56)\end{array}$ & $\begin{array}{l}6.08 \\
(1.68)\end{array}$ & $\begin{array}{l}5.48 \\
(2.07)\end{array}$ \\
\hline $\begin{array}{l}\text { N of orthographic } \\
\text { neighbors }\end{array}$ & $\begin{array}{l}3.51 \\
(3.29)\end{array}$ & $\begin{array}{l}3.83 \\
(4.68)\end{array}$ & $\begin{array}{l}2.71 \\
(4.17)\end{array}$ & $\begin{array}{l}4.88 \\
(5.32)\end{array}$ \\
\hline $\begin{array}{l}\text { Neighbors' } \\
\text { frequency }\end{array}$ & $\begin{array}{l}49.96 \\
(93.93)\end{array}$ & $\begin{array}{l}129.175 \\
(289.37)\end{array}$ & $\begin{array}{l}15.33 \\
(40.64)\end{array}$ & 19.87 \\
\hline OLD & $\begin{array}{l}1.66 \\
(0.57)\end{array}$ & $\begin{array}{l}1.45 \\
(0.44)\end{array}$ & $\begin{array}{l}1.79 \\
(0.70)\end{array}$ & $\begin{array}{l}1.63 \\
(0.81)\end{array}$ \\
\hline Arousal & $\begin{array}{l}5.30 \\
(0.45)\end{array}$ & $\begin{array}{l}5.29 \\
(0.61)\end{array}$ & $\begin{array}{l}5.27 \\
(1.32)\end{array}$ & $\begin{array}{l}5.74 \\
(0.79)\end{array}$ \\
\hline Valence & $\begin{array}{l}4.69 \\
(1.06)\end{array}$ & $\begin{array}{l}4.27 \\
(1.08)\end{array}$ & $\begin{array}{l}3.98 \\
(1.53)\end{array}$ & $\begin{array}{l}4.05 \\
(1.59)\end{array}$ \\
\hline
\end{tabular}

Note: Italian: Written frequency was extracted from SUBTLEX-IT (Crepaldi et al., 2013); number of orthographic neighbors and neighbors' frequency were calculated on CoLFIS (Bertinetto et al., 2005); valence and arousal were extracted from ITABÙ (Sulpizio et al., 2018) and the Italian ANEW, respectively. English: Written frequency was extracted from SUBTLEX-UK (van Heuven et al., 2014); number of orthographic neighbors and neighbors' frequency were calculated with MCWord (Medler \& Binder, 2005); valence and arousal were extracted from Janschewitz' (2008) database.

\section{Procedure.}

Before coming to the lab, participants were required to complete the on-line Cambridge test and the translation task; based on their performance they were enrolled in the monolingual or bilingual group (participants with intermediate levels of proficiency were not enrolled).

Monolinguals. Participants performed a visual lexical decision task in the scanner within an event- 
related design. Each trial started with a fixation cross presented for $500 \mathrm{~ms}$ in the center of the screen; then, the target stimulus (either a word or a pseudoword) was displayed for $500 \mathrm{~ms}$ and replaced by a question mark for $2000 \mathrm{~ms}$; the screen was then cleared, with a blank screen remaining for a random inter-stimulus interval ranging from 1036 to $4784 \mathrm{~ms}$. Participants were asked to indicate whether each stimulus was a real word or not. Responses were given by pressing one of two buttons on a response box. Reaction times (RTs) were measured as the time of the first key press after word onset. Stimuli were arranged into blocks of 14 trials each, with a rest signal (***) appearing between blocks for 14 secs; stimuli were presented in a pseudorandomized order. The experiment was preceded by a short practice session. The total acquisition time of the run was $\sim 15$ minutes.

After the fMRI experiment, participants completed a questionnaire in which they were asked to evaluate the words they saw in the experiment for their offensiveness on a 1 (not offensive at all) to 7 (highly offensive) scale.

Bilinguals. The procedure was identical to that implemented with monolinguals, with the only difference that bilinguals performed two runs, one with the Italian (L1) stimuli and one with the English (L2) stimuli; the order of runs was counterbalanced across participants. The total acquisition time of the run was $\sim 30$ minutes.

At the end of the experiment, participants filled in the questionnaires with the subjective measures of L2 AoA, proficiency, and exposure, and the questionnaire in which they rated the both the English and Italian experimental stimuli on offensiveness on a 1 (not offensive at all) to 7 (highly offensive) scale; for English stimuli, participants were also asked to indicate whether they knew them or not.

\section{Imaging methods.}

\section{MRI acquistion.}


MR images were acquired with a 3Tesla Philips Ingenia CX MR system (Philips HealthCare, Best, Netherlands) equipped with a 32 channels SENSE head coil, at the C.E.R.M.A.C. at Unit of Neuroradiology at Hospital San Raffaele in Milan (Italy). Functional scans were acquired with a fast speed Echo Planar Imaging (EPI) sequence (Echo Time [TE] = 33 ms; Repetition Time [TR $=3000$ ms; Flip Angle $[\mathrm{FA}]=85^{\circ}$; number of volumes per run $=294$; Field of View $[\mathrm{FOV}]=240 \times 240$; matrix size $=80 \times 80 ; 38$ axial slices per volume; slice thickness $=3$; interslice gap $=0.75$; voxel size $=$ $3 \times 3 \times 3$; Phase Encoding direction $[\mathrm{PE}]=\mathrm{A} / \mathrm{P}$; SENSE factor $=1.9$; Multiband factor $=2$; whole brain coverage). Ten dummy scans preceded each run to optimize EPI image signal. In addition, for all subjects, a high-resolution T1-weighted structural MRI was obtained $(\mathrm{TE}=4.8 \mathrm{~ms} ; \mathrm{TR}=9.97 \mathrm{~ms} ; \mathrm{FA}=$ $8^{\circ} ; \mathrm{FOV}=269 \times 269$; matrix size $384 \times 384 ; 243$ axial slices; slice thickness $=1.4$; voxel size $=0.7 \times$ 0.7 x 0.7 isotropic; $\mathrm{PE}$ direction $=\mathrm{R} / \mathrm{L}$; whole brain coverage).

fMRI pre-processing.

Data were preprocessed and analyzed using Statistical Parametric Mapping (SPM12; Wellcome Department of Cognitive Neurology, London, UK) (SPM v6906) and Matlab 2013b. Prior to analysis, all images underwent a series of preprocessing steps. The origin of each structural T1-weighted volume was first manually set to match the Anterior Commissure -Posterior Commissure (AC-PC) line. Each volume was then bias-corrected for intensity inhomogeneities and segmented using the "unified segmentation and normalization" function in SPM12 (Ashburner \& Friston, 2005). Functional volumes were first slice-time corrected using sinc interpolation to correct for the different sampling times of the slices (reference point $1^{\text {st }}$ slice), then realigned to the first volume and unwarped to correct for motion artifacts and geometric distortions. Realigned functional volumes were then coregistered to the biascorrected structural brain image and normalized to the standard Montréal Neurological Institute (MNI) 152 subjects average template through the segmentation derived spatial transformations. After 
normalization, volumes were resampled to $2 \times 2 \times 2 \mathrm{~mm}$ voxels. Finally, the functional volumes were smoothed with an $8 \mathrm{~mm}$ full width at half-maximum (FWHM) Gaussian kernel, in order to account for any residual between-subject variation and increase the signal-to-noise ratio (Friston et al., 1995).

\section{Univariate analysis.}

Functional data were analyzed using SPM12 employing a random effects model implemented into a two-level summary statistic approach. In the first-level analysis, evoked responses for experimental conditions were entered into a General Linear Model (GLM) and modeled with the canonical haemodynamic function (HRF). For the monolingual participants, onsets for the different types of words [Non-taboo; Taboo] were specified. For the bilingual participants, the onsets of the different types of words were specified both for the Italian session, and for the English session. A set of Student's t-test linear contrasts were defined to use the estimated con-images at the second statistical level. For monolinguals, the first level analysis resulted in one contrast image, i.e., word type [Nontaboo > Taboo]; for bilinguals, instead, the following contrast images were estimated: Word type [Nontaboo $>$ Taboo], language [English $>$ Italian], and the interaction [(Italian_Non-taboo $>$ Italian_Taboo)

$>$ (English_Non-taboo $>$ English_Taboo)]. Temporal autocorrelation was treated with an AR(1) regression algorithm setting a high-pass filter of $128 \mathrm{~s}$.

At the second level of analysis, the contrast images obtained at the single-subject level were used to compute one sample t-tests assessing their significance at the group level. Voxel-wise whole brain analysis was performed with cluster-level multiple comparison correction. Statistical threshold was set at cluster level at $\mathrm{p}<.05$ family-wise error corrected (FWE) and at voxel level at $\mathrm{p}<.001$. Multivariate analysis.

Multi-voxel pattern analysis (MVPA) examines the pattern of brain activity across multiple voxels, allowing to detect differences that otherwise would be undetectable (because associated to 
spatially distributed patterns and not to single voxel responsivity; e.g., Haynes \& Rees, 2006). This method is thus suitable for investigating where in the brain a particular cognitive dimension is represented, or whether a particular region is sensitive to a particular dimension of knowledge. We used MVPA with the aim to investigate whether distributed brain activity patterns may differ when processing taboo-laben words of different categories (taboo vs. non-taboo), and whether differentiation occurs at different level for L1 and L2.

The Decoding Toolbox (TDT, Hebart et al., 2015) was used for MVPA. The estimated beta images of the GLM were used as the basis for linear support vector machine (SVM) classification (regularization parameter $\mathrm{C}=1$ ). Classifications were performed between subjects by means of a leaveone-subject-out cross-validation in monolinguals and bilinguals; for the latter, in order to compare for discrimination patterns in L1 and L2, classification was performed in both languages.

We performed a searchlight analysis with a $4 \mathrm{~mm}$ radius sphere moving across the whole brain; moved across the entire brain by taking each voxel in the volume as the searchlight center. For each sphere, a SVM was trained and tested as described above, and the classification accuracy score was assigned to the central voxel. Significance of each accuracy score was tested by means of binomial test; only results surviving the Bonferroni correction were considered.

\section{Results}

\section{Behavioral results}

Figure 1 reports mean RTs, accuracy, and offensive ratings for conditions and groups. All the three measures were analyzed in order to investigate potential differences in the processing of non-taboo words and taboo words in L1 and L2.

For monolinguals, the one-way ANOVA with word type (non-taboo vs. taboo) as within- 
participants factor showed that taboo words were categorized more slowly than non-taboo words (F $(1,19)=7.05, \mathrm{p}=.01)$; moreover, taboo words were numerically (but not significantly: $\mathrm{F}<.1, \mathrm{p}>.3$ ) more accurate than non-taboo words. The offensiveness range was 1-1.3 for non-taboo words and was 2.4-6.4 for taboo words; the analysis showed that taboo words were rated as more offensive than nontaboo words $(\mathrm{F}(1,19)=137.30, \mathrm{p}<.001)$.

Bilinguals reported to have an excellent knowledge of the English items (overall percentage of known items: 98\%). For bilinguals, the dependent measures were analyzed by means of a 2 x 2 ANOVA, with word type (non-taboo vs. taboo) and language (Italian vs. English) as within-participants factor ${ }^{2}$. The analyses of RTs did not show any significant effect (all Fs $<4, \mathrm{ps}>.06$ ). The analysis of accuracy showed a main effect of word type: Bilinguals were more accurate in categorizing taboo words than non-taboo words $(\mathrm{F}(1,21)=23.64, \mathrm{p}<.001)$; also the main effect of language was significant $(\mathrm{F}(1,21)=6.97, \mathrm{p}=.01)$, with a slightly higher accuracy in L1 than in L2; the interaction was not significant $(\mathrm{F}<2.1, \mathrm{p}>.1)$.

With regard to offensiveness, the ratings were in the range 1-2.28 for non-taboo and 1.89-5.57 for taboo words for the bilinguals' L1, and in the range 1-1.83 for non-taboo words and 1.51-6.11 for taboo words for the bilinguals' L2. The analysis of offensiveness showed a significant main effect of word type $(\mathrm{F}(1,21)=95.61, \mathrm{p}<.001)$ and a significant interaction between word type and language $(\mathrm{F}$ $(1,21)=17.91, p<.001)$ : Inspection of the interaction by means of multiple comparisons (Bonferroni corrected) showed that taboo words were rated as more offensive than non-taboo words both in L1 (p $<.001)$ and in L2 $(\mathrm{p}<.001)$; more interestingly, taboo words were rated as more offensive in L1 than in L2 $(p=.05)$, whereas no difference emerged for non-taboo words between the two languages $(p>.4)$. The effect of language was not significant $(F<1, p>.3)$.

2 Three neutral words (jolt, lard, maggot) were removed from these and the following analyses because their accuracy was below $3 \mathrm{SD}$ from the average accuracy. One participant was discarded from the RT analysis because she/he was $3 \mathrm{SD}$ slower than the average performance. 
Figure 1. Mean latencies for correct responses, percentage of accuracy, and offensiveness by condition (with standard errors) for monolinguals and bilinguals.
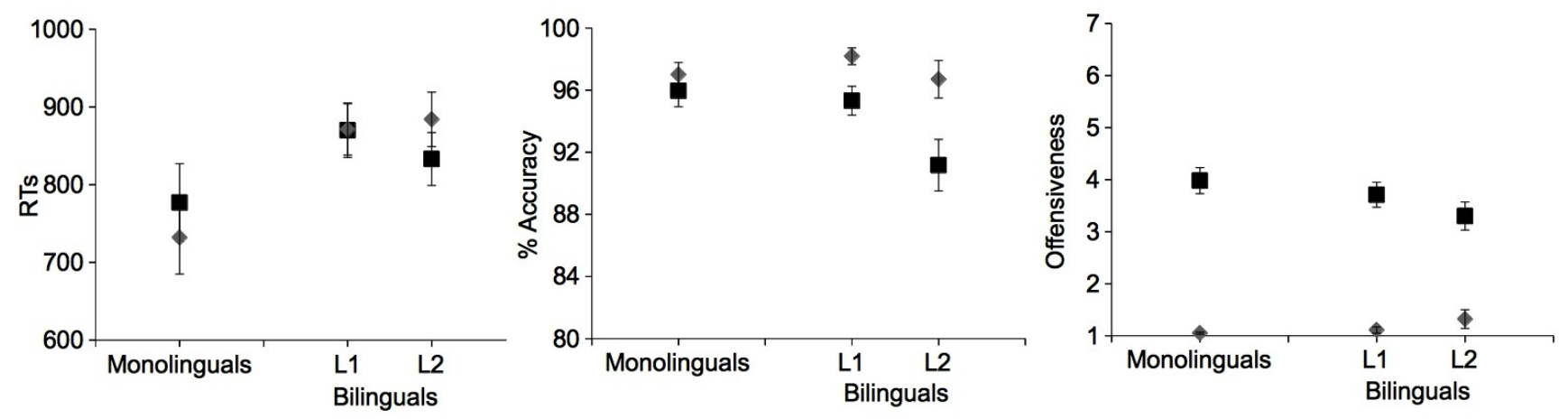

Taboo words

Non-taboo words

fMRI Results - Univariate analysis

Monolinguals. Table 3 reports the fMRI results for the monolingual group. The analysis showed that, compared to taboo words, non-taboo words elicited greater activation in: Inferior occipital gyrus, including the fusiform gyrus, bilaterally, precentral gyrus, left supplementary motor cortex, left postcentral gyrus, and left putamen (see Figure 2). No region showed higher activation for taboo words than non-taboo words.

Table 3. Results for monolinguals.

\begin{tabular}{|c|c|c|c|c|c|c|c|}
\hline \multirow[b]{2}{*}{ Cortical region } & \multirow[b]{2}{*}{ BA } & \multirow[b]{2}{*}{ Cluster size } & \multirow[b]{2}{*}{ Z-value } & \multirow[b]{2}{*}{$p$ value } & \multicolumn{3}{|c|}{$\begin{array}{l}\text { MNI coordinates } \\
(\mathrm{mm})\end{array}$} \\
\hline & & & & & $\mathrm{x}$ & $\mathrm{y}$ & $\mathrm{z}$ \\
\hline \multicolumn{8}{|l|}{ Non-taboo $>$ Taboo } \\
\hline Left Inferior Occipital Gyrus & 19 & 1224 & 5.58 & .000 & -34 & -86 & -4 \\
\hline Left Precentral Gyrus & 6 & 1161 & 5.48 & .000 & -50 & 0 & 36 \\
\hline Right Inferior Occipital Gyrus & 18 & 834 & 5.24 & .000 & 32 & -90 & -2 \\
\hline Left Putamen & -- & 740 & 4.5 & .000 & -20 & 8 & 6 \\
\hline Left Supplementary Motor Cortex & 6 & 485 & 4.08 & .001 & -8 & -2 & 52 \\
\hline
\end{tabular}




\begin{tabular}{|l|l|l|l|l|l|l|l|}
\hline Left Postcentral Gyrus & 3 & 1241 & 4.07 & .000 & -38 & -30 & 48 \\
\hline & & & & & & & \\
\hline Taboo $>$ Non-taboo & & & & & & & \\
\hline-- & -- & - & - & & -- & -- & -- \\
\hline
\end{tabular}

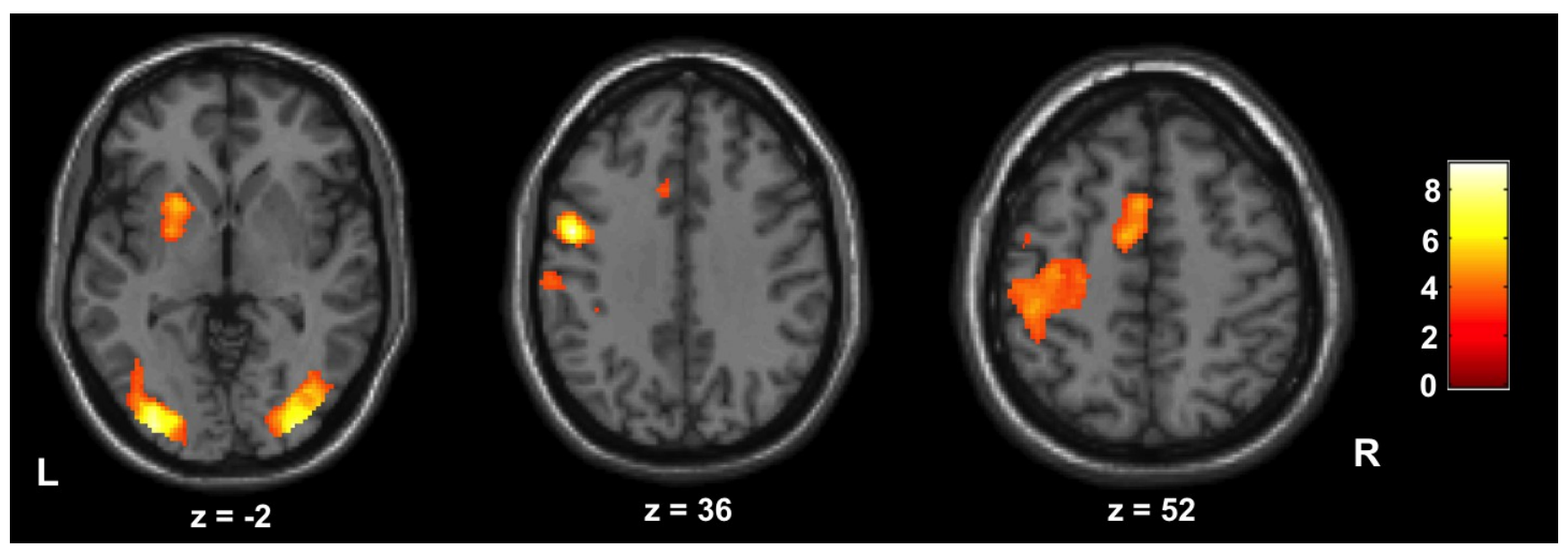

Figure 2. Brain activations of the Non-taboo $>$ Taboo contrast for the monolingual participants (cluster size criterion: 450 voxels).

Bilinguals. Results for the bilingual groups are showed in Table 4 and Figure 2. The results for the Word type contrasts showed that, compared to taboo words, non-taboo words elicited greater activation in: fusiform gyrus bilaterally, precentral gyrus bilaterally, left supplementary motor cortex, operculum bilaterally, left putamen, and right caudate (Non-taboo $>$ Taboo). No region showed higher activation for taboo words than non-taboo words (Taboo $>$ Non-taboo). The results for Language showed higher activation for L2 than L1 (L2 > L1) in the: inferior occipital gyrus bilaterally, left middle frontal gyrus, right inferior frontal gyrus, left putamen, right thalamus, cerebellum bilaterally; these regions are typically reported in bilinguals studies (e.g., Abutalebi, Della Rosa, Gonzaga, Keim, Costa, \& Perani, 2013; Rossi, Newman, Kroll, Diaz, 2018). No higher activation for L1 over L2 was found (L1 > L2). The Word Type by Language interaction effect yielded significant activations in the inferior occipital gyrus bilaterally, and left anterior cingulate gyrus. The inspection of the directionality of the estimates for each of the four experimental conditions indicates that, in all brain regions, the interaction 
effects were driven by a difference in the response to taboo words in L1 and L2, with a selective signal increase for the processing of taboo stimuli in L2 (Table 4, Figure 3).

A further control analysis was run in order to test whether the contrasts [Taboo>Non-taboo] and [Non-taboo>Taboo] for the bilinguals' L1 showed the same patterns of activation than in monolinguals. The analysis showed no effect for the [Taboo $>$ Non-taboo] contrast; instead, compared to taboo words, non-taboo words elicited greater activation in: inferior occipital gyrus bilaterally, precentral gyrus bilaterally, left postcentral gyrus, right superior parietal lobule, and left supplementary motor cortex. The pattern is analogous to that reported for monolinguals, indicating that knowing a second language does not change how taboo and non-taboo words are processed in the first language. 
Table 4. Results for Bilinguals.

\begin{tabular}{|c|c|c|c|c|c|c|c|}
\hline \multirow[b]{2}{*}{ Cortical region } & \multirow[b]{2}{*}{ BA } & \multirow[b]{2}{*}{ Cluster size } & \multirow[b]{2}{*}{ Z-value } & \multirow[b]{2}{*}{$\mathrm{p}$ value } & \multicolumn{3}{|c|}{$\begin{array}{l}\text { MNI coordinates } \\
(\mathrm{mm})\end{array}$} \\
\hline & & & & & $\mathrm{x}$ & $\mathrm{y}$ & $\mathrm{z}$ \\
\hline \multicolumn{8}{|l|}{ Non-taboo $>$ Taboo } \\
\hline Left Precentral Gyrus & 6 & 3812 & 5.72 & .000 & -46 & -2 & 44 \\
\hline Left Fusiform Gyrus & 37 & 953 & 5.05 & .000 & -40 & -52 & -20 \\
\hline Left Supplementary Motor Cortex & 6 & 848 & 4.65 & .000 & -6 & 6 & 54 \\
\hline Right Frontal Operculum & 47 & 505 & 4.62 & .000 & 44 & 22 & -4 \\
\hline Right Precentral Gyrus & 44 & 243 & 4.53 & .019 & 44 & 4 & 30 \\
\hline Right Occipital Fusiform Gyrus & 37 & 927 & 4.49 & .000 & 40 & -62 & -14 \\
\hline Left Central Operculum & 48 & 259 & 4.42 & .015 & -54 & -20 & 20 \\
\hline Right Inferior Occipital Gyrus & 19 & 272 & 4.37 & .012 & 32 & -88 & -6 \\
\hline Left Putamen & -- & 325 & 4.24 & .005 & -20 & 10 & 8 \\
\hline Right Caudate & -- & 244 & 4.15 & .019 & 20 & 14 & 6 \\
\hline \multicolumn{8}{|l|}{ Taboo $>$ Non-taboo } \\
\hline-- & -- & -- & -- & & -- & -- & -- \\
\hline \multicolumn{8}{|l|}{$L 1>L 2$} \\
\hline-- & -- & -- & -- & & -- & -- & -- \\
\hline \multicolumn{8}{|l|}{$L 2>L 1$} \\
\hline Right Thalamus & -- & 1956 & 5.53 & .000 & 14 & -32 & 2 \\
\hline Left Cerebellum & -- & 466 & 4.83 & .000 & -10 & -82 & -36 \\
\hline Left Cerebellum & -- & 594 & 4.75 & .000 & -44 & -64 & -38 \\
\hline Left Calcarine Cortex & 18 & 341 & 4.58 & .002 & -14 & -86 & -4 \\
\hline Right Inferior Frontal Gyrus - pars triangularis & 45 & 558 & 4.52 & .000 & 50 & 34 & 2 \\
\hline Right Cerebellum & -- & 271 & 4.49 & .006 & 14 & -60 & -50 \\
\hline Left Putamen & -- & 172 & 4.43 & .044 & -20 & 10 & -16 \\
\hline Left Middle Frontal Gyrus & 46 & 307 & 4.35 & .003 & -26 & 46 & 24 \\
\hline Right Inferior Occipital Gyrus & 18 & 183 & 4.28 & .035 & 30 & -92 & -4 \\
\hline \multicolumn{8}{|l|}{ Interaction } \\
\hline Right Inferior Occipital Gyrus & 19 & 960 & 4.32 & .000 & 32 & -86 & -4 \\
\hline Left Inferior Occipital Gyrus & 18 & 430 & 4.26 & .002 & -24 & -88 & -4 \\
\hline Left Anterior Cingulate Gyrus & 24 & 260 & 3.92 & .02 & -8 & 10 & 34 \\
\hline
\end{tabular}




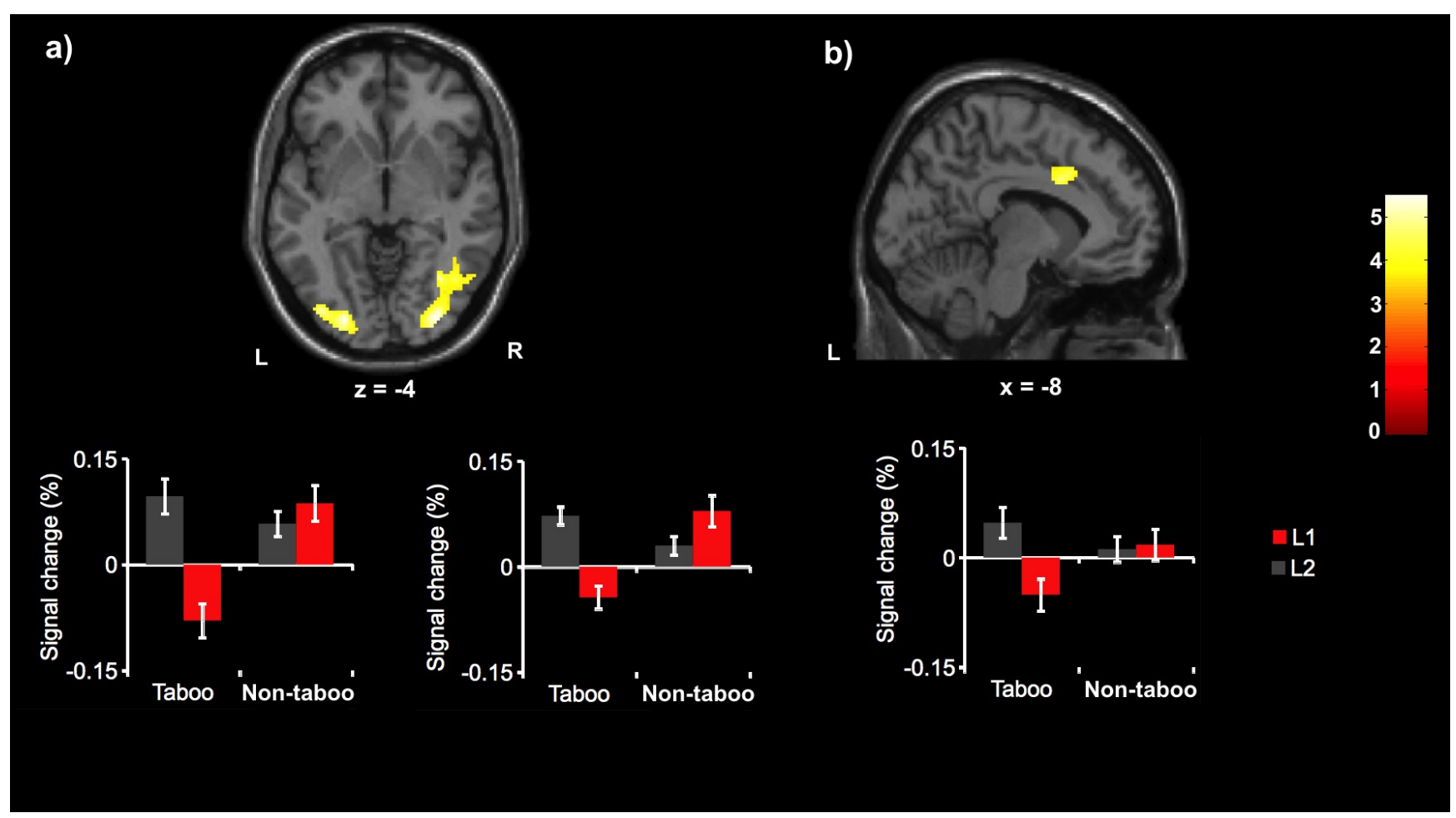

Figure 3. Brain activations for the interaction between word type and language at occipital sites bilaterally (a) and left cingulate cortex (b), and percentage of signal change for conditions for taboo and non-taboo words in each language (red = L1; grey = L2) (cluster size criterion: 250 voxels).

\section{fMRI Results - Multivariate analysis}

Figure 4 reports regions in which the L1 and L2 word discrimination analyses yielded significantly above-chance accuracy. The analysis of word type discrimination in monolinguals shows a small set of cortical regions in both hemispheres, with a slight prevalence of the left hemisphere. Discriminative regions were found in the: inferior occipital gyrus bilaterally, $(x=-30, y=-74, z=-6$, Accuracy $=$ $92.1 \%$ and $\mathrm{x}=40, \mathrm{y}=-74, \mathrm{z}=12$, Accuracy $=89.47 \%)$; fusiform gyrus bilaterally $(\mathrm{x}=-36, \mathrm{y}=-84, \mathrm{z}$ $=-14$, Accuracy $=89.47 \%$ and $x=34, y=-68, z=-12$, Accuracy $=94.73 \%)$; left lingual gyrus $(x=-32$, $y=-84, z=-14$, Accuracy $=94.73 \%)$; left cerebellum $(x=-28, y=-82, z=-18$, Accuracy $=92.1 \%)$.

These results largely converge with those of the univariate analysis. Similar patterns were also reported for bilinguals' L1, with a slightly larger set of discriminative regions: inferior occipital gyrus bilaterally $(x=-26, y=-92, z=-4$, Accuracy $=88.63 \%$ and $x=26, y=-90, z=-4$, Accuracy $=88.63 \%)$; fusiform 
gyrus bilaterally $(x=-36, y=-84, z=-14$, Accuracy $=88.63 \%$ and $x=22, y=-36, z=-12$, Accuracy $=$ $88.63 \%$ ), lingual gyrus bilaterally $(x=-30, y=-82, z=-12$, Accuracy $=90.9 \%$, and $x=22, y=-92, z$ $=-6$, Accuracy $=90.9 \%)$, left middle occipital gyrus $(x=-28, y=-92, z=-2$, Accuracy $=90.9 \%)$; left supplementary motor area $(x=-8, y=4, z=62$, Accuracy $=88.63 \%)$; right frontal operculum $(x=42$, $y=4, z=14$, Accuracy $=88.63 \%)$; right cuneus $(x=16, y=-92, z=16$, Accuracy $=93.18 \%)$; left precentral gyrus $(x=-34, y=6, z=44$, Accuracy $=90.9 \%)$; left postcentral gyrus $(x=-42, y=-14, z=$ 46 , Accuracy $=90.9 \%)$; left middle cingulate cortex $(x=-4, y=-28, z=40$, Accuracy $=88.63 \%)$.

The analysis performed on bilinguals' L2, however, showed a markedly different pattern of discrimination, with a selective involvement of a few regions different from those reported for monolinguals and bilinguals' L1. Specifically, discriminative regions for L2 were found in the: left insula $(x=-28, y=14, z=8$, Accuracy $=88.63 \%)$, right calcarine sulcus $(x=8, y=-72, z=18$, Accuracy $=88.63 \%$ ), and right preSMA/dACC complex (pre-Supplementary Motor Area/dorsal anterior cingulate cortex $)(x=8, y=22, z=48$, Accuracy $=88.63 \%)$. 


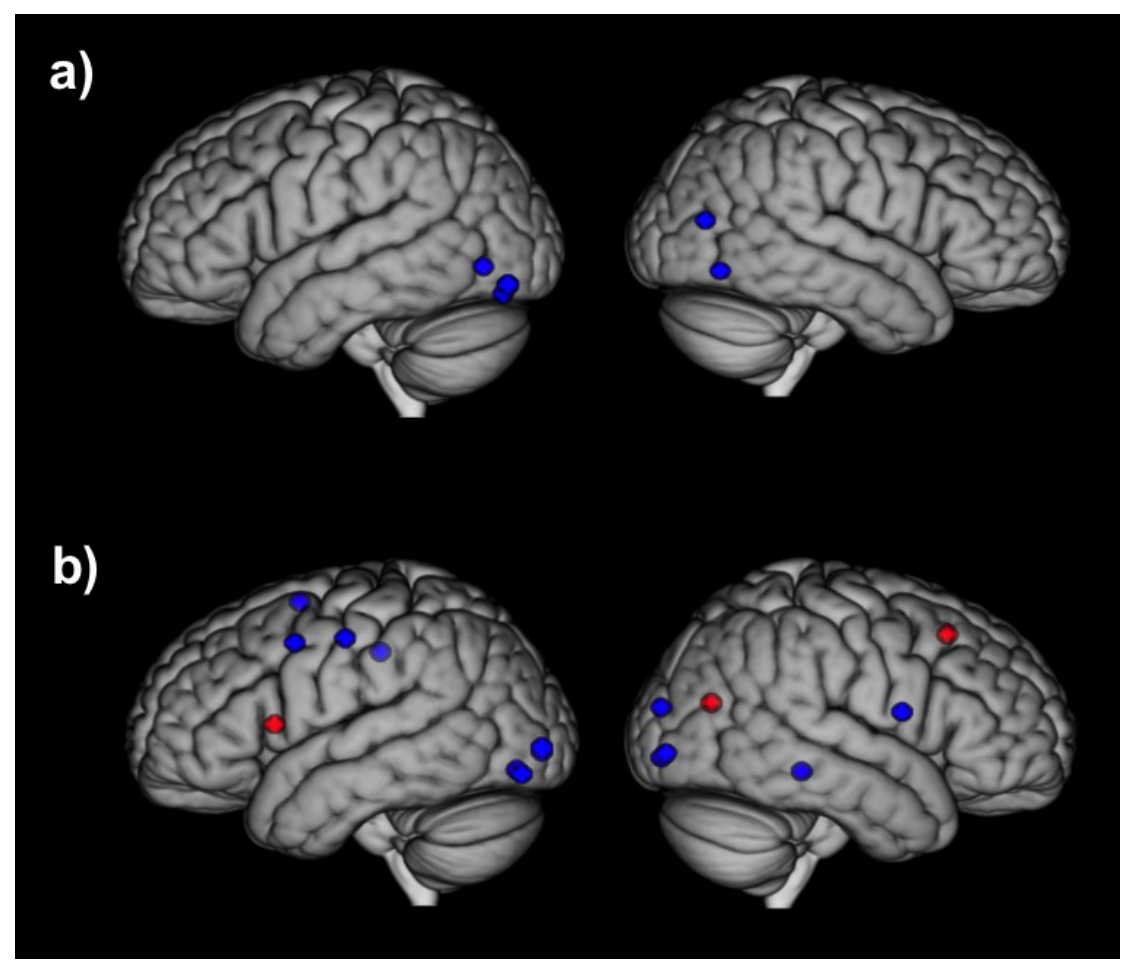

Figure 4. Distribution of the regions discriminating between Taboo and Non-taboo words; a) results for monolinguals; b) results for bilinguals' L1 (blue) and L2 (red).

\section{Discussion}

Two event-related fMRI experiments were conducted with two aims: 1) identifying the neural correlates of taboo words; and 2) investigating whether these correlates are similar when processing occurs in L1 and L2. We start by addressing our first aim and discuss the results for both monolinguals and bilinguals' L1; we then address our second aim by mainly discussing the results for bilinguals' L2.

Taboo words were perceived as more offensive than non-taboo words, confirming the inappropriateness of the taboo stimuli used and in line with previous behavioral findings (Cepollaro, Sulpizio, \& Bianchi, 2019; Janschewitz, 2008). Across participants, the contrast of non-taboo words versus taboo words in the univariate analysis showed activation in a set of cortical and subcortical structures: the occipital gyrus bilaterally, including the fusiform gyrus and lingual gyrus (as revealed by 
MVPA), the left precentral gyrus, the left SMA and the left putamen. The same pattern was reported for brain activations in both monolinguals and bilinguals, suggesting that bilingualism does not affect underlying processing of word recognition in native language (see also, Palomar-Garcia, Bueichekú, Ávila, Sanjuán, Strijkers, Ventura-Campos, \& Costa, 2015).

The reported regions are part of the reading network, but some of them have been also reported to respond to the emotional and/or social dimension of the stimuli. Especially the left fusiform gyrus in the occipital cortex is a core component of the reading network, specialized in extracting and storing abstract patterns from visual(-orthographic) information (e.g., Dehaene \& Cohen, 2011; Price, 2012). Its activation is also a function of word typicality, with larger activation for pseudowords or infrequent/unfamiliar words (Taylor, Rastle, \& Davis, 2012); thus, our results suggest that taboo words are more word-like than non-taboo words, the latter requiring more visuo-orthographic processing to be recognized. This interpretation is also supported by the higher activation for non-taboo words in the left precentral gyrus and SMA, areas responsible for phonological processing in word recognition and reading (Martin, Schurz, Kronbichler, \& Richlan, 2015). It is interesting to note that no effect for the contrast taboo words/non-taboo words was found. The asymmetry in the results might be interpreted, prima facie, as suggesting that taboo words are processed differently from non-taboo words (e.g., van Lancker \& Cummings, 1999). However, in absence of any clear dissociation, and in accordance with the literature on emotionally-laden words (e.g., Chen et al., 2015), it seems to us more parsimonious to interpret our results in terms of a quantitative - not qualitative - difference between taboo and nontaboo words: both types of words are processed by means of the same neural networks, but the processing of taboo words is more efficient than that of non-taboo words.

Some studies have shown that the activation of the occipital cortex is modulated by the stimulus' emotional content. In their lexical decision experiment with Chinese-English bilinguals, Chen 
and colleagues (2015) found that emotional words elicited weaker activation than neutral words in the left middle occipital gyrus; the authors interpreted this finding as reflecting the amount of effort participants need to recognize the stimulus, with emotional connotation facilitating recognition. A similar explanation may hold here: a weaker involvement of the occipital structures for taboo words suggests that, similarly to emotional information, social (and possibly emotional) relevance is automatically accessed in one's L1, facilitating word recognition. Indeed, occipital regions have been suggested to be relevant for social perceptual processing (Van Overwalle, 2009).

Non-taboo words were also associated to a higher involvement of the left putamen, a subcortical structure involved in several cognitive functions, as, e.g., contextual learning (Kimura, 1990), cognitive control (Abutalebi et al., 2013), and language (e.g., Rossell, Bullmore, Williams, \& David, 2001). With regard to the latter, the putamen has been suggested to play a relevant role in semantic processing and retrieval, as observed in different lexical decision and reading experiments (e.g., Carreiras, Mechelli, Estevez, \& Price, 2007; Rossell et al., 2001; Viñas-Guasch \& Wu, 2017). In our lexical decision study, the larger recruitment of the left putamen when processing non-taboo stimuli may have two complementary interpretations. First, compared to taboo words, non-taboo words might be associated to a more extended semantic processing, thus triggering a more extended activation due to a wider range of lexical and contextual usability. This interpretation is also supported by the involvement of the lingual gyrus (as revealed by the MVPA) in the discrimination between taboo and non-taboo stimuli; the lingual gyrus has been shown to contribute to the integration of different types of language-independent semantic information, working as a hub across different semantic contexts and supporting semantic categorization (Musz \& Thompson-Schill, 2015; Van de Putte, De Baene, Price, \& Duyck, 2018). With respect to the second interpretation, together with other striatal regions, the putamen has been found to be sensitive to the emotional and social valence of stimuli, with greater activation for positive and rewarding versus neutral or negative stimuli (e.g., Bhanji \& Delgado, 2014; 
Hamann \& Mao, 2002; Singer, Kiebel, Winston, Dolan \& Frith, 2004). One might thus speculate that socially inappropriate and offensive words engage less reward-related activity in the striatal region and are thus associated to a weaker involvement of the left putamen.

Do the intensity and the neuroanatomical loci associated with taboo stimuli differ between L1 and L2?

Behavioral and fMRI results provide converging evidence that differences exist in the way taboo words and non-taboo words are processed in L1 and L2. Behaviorally, while non-taboo words were perceived similarly (in)offensive independently of the language in which they were presented, taboo words were perceived as less offensive when presented in the foreign rather than native language. Neurally, language modulated word processing in two regions, with a selective signal increase for taboo words: the inferior occipital gyrus bilaterally and the anterior cingulate gyrus (ACC).

The additional engagement of occipital structures suggests that, when a foreign language is used, taboo words need more effort to be processed; differently from what happens in L1, sociopragmatic and emotional semantic information does not seem to support word recognition in visual areas (see Chen et al., 2015). The reason may be a less automatized access to socio-pragmatic and emotional information in a foreign language (Hayakawa et al., 2016) caused by a weaker link between the word-form representation and the non-linguistic semantic system (in particular, socio-pragmatic knowledge) in the bilinguals' L2.

The ACC is part of the limbic system and is involved in both cognitive and affective regulation (e.g., Del Maschio et al., 2018; Etkin, Egner, \& Kalish, 2011). However, especially the ACC-gyrus plays a role in social cognition as well, being involved in the processing of social norm representation and violation (Zinchenko et al., 2017). Accordingly, our results indicate that the processing of sociopragmatic inappropriate linguistic stimuli is associated with an involvement of the ACC gyrus. This being the case, a selective recruitment of the ACC in L2 may be based on the fact that, differently from 
other lexico-semantic categories, we learn taboo words and their use through social interaction (Jay, 2009). Although highly proficient, our bilinguals living predominantly in Italy do not report a balanced use of their languages. A similar linguistic profile, i.e., unequal exposure to L2, might render speakers less confident about their own social understanding/evaluation in L2, as they may feel that such understanding/evaluation is based on a shallow intuition rather than on a real socio-pragmatic competence (cf. Geipel et al., 2015). This weak confidence would need a greater reliance on social norm representation and evaluation, reflected in a larger involvement of the ACC-gyrus. This interpretation is supported by our MVPA results, showing that, in L2, the taboo/non-taboo discrimination also involves the left insula: these two tightly connected structures are part of the saliency network, which selects the most relevant stimuli in order to guide behavior (Taylor, Seminowicz, \& Davis, 2009). The insula is also associated with affective experience and with the processing of social norm violation (e.g., Guroglu, van den Bos, Rombouts, \& Crone, 2010). Di Cesare and colleagues (2017) showed that, compared to a neutral control condition, producing and perceiving socially-characterized speech acts increases left insula response. Along similar lines, in our study the left insula may contribute to identify words as socially appropriate or not, and the contribution of the ACC would be particularly important when the speakers use a foreign language, which is supposed to attenuate the link between social norms and language. Socio-pragmatic knowledge may be less accessible in L2: especially when the foreign language is used in a primarily L1 context, it might trigger a reduced activation of moral and socio-cultural norms (Geipel et al., 2015). Note that this reduced activation might be affected by the frequency of swearing in L1 and L2. To our knowledge, there are no available data on this issue. By and large, it might be assumed that the frequency of swearing in L2 is related to L2 exposure (i.e., the more a person is exposed to a language, the more frequently she/he is exposed to taboo words); since our proficient bilinguals were less exposed to L2 than L1, one might speculate that the frequency of taboo words in L2 may have contributed to the 
observed interaction, by reducing the accessibility to socio-cultural norms. Future studies should consider both L2 exposure and L2 frequency of swearing to disentangle the potential role of both factors on the processing of taboo words in a foreign language.

To conclude, other than being useful to construct a neurocognitively plausible theory of taboo words (Jay, 2009), our findings contribute to the understanding of a fundamental though often overlooked issue, i.e., how language affects people. Less effort is needed to process taboo words than non-taboo words, suggesting that, similarly to emotional information, socio-pragmatic knowledge is automatically accessed and facilitates word recognition. However, this only holds when the processing takes place in the speaker's L1; when a foreign language is used, the processing of taboo words is less automatized and requires additional structures related to social norm representation and evaluation. As the competence about whether a word is contextually appropriate is learnt through social interaction, it may be harder for a speaker to access socio-pragmatic norms when a language is used sporadically in context. 


\section{References}

Abutalebi, J., Della Rosa, P. A., Gonzaga, A. K. C., Keim, R., Costa, A., \& Perani, D. (2013). The role of the left putamen in multilingual language production. Brain and Language, 125, 307-315.

Abutalebi, J., Della Rosa, P. A., Green, D. W., Hernandez, M., Scifo, P., Keim, R., ... \& Costa, A. (2012). Bilingualism tunes the anterior cingulate cortex for conflict monitoring. Cerebral Cortex, 22, 2076-2086.

Ashburner, J., \& Friston, K. J. (2005). Unified segmentation. Neuroimage, 26, 839-851.

Bertinetto, P.M. Burani, C., Laudanna, A.,Marconi, L., Ratti, D., Rolando, C., \& Thorton, A. M. (2005). Corpus e Lessico di frequenza dell'italiano scritto (CoLFIS) [CoLFIS. Corpus and frequency lexicon of written Italian]. Retrieved from http://www.istc.cnr.it/material/database/colfis/index_eng.shtml

Bhanji, J. P., \& Delgado, M. R. (2014). The social brain and reward: social information processing in the human striatum. Wiley Interdisciplinary Reviews: Cognitive Science, 5, 61-73.

Canini, M., Della Rosa, P. A., Catricalà, E., Strijkers, K., Branzi, F. M., Costa, A., \& Abutalebi, J. (2016). Semantic interference and its control: A functional neuroimaging and connectivity study. Human brain mapping, 37, 4179-4196.

Carreiras, M., Mechelli, A., Estévez, A., \& Price, C. J. (2007). Brain activation for lexical decision and reading aloud: two sides of the same coin?. Journal of cognitive neuroscience, 19, 433-444.

Cepollaro, B., Sulpizio, S., \& Bianchi, C. (2019). How bad is it to report a slur? An em- pirical investigation. Journal of Pragmatics, 146, 32-42.

Chen, P., Lin, J., Chen, B., Lu, C., \& Guo, T. (2015). Processing emotional words in two languages with one brain: ERP and fMRI evidence from Chinese-English bilinguals. Cortex, 71, 34-48.

Costa, A., Foucart, A., Hayakawa, S., Aparici, M., Apesteguia, J., Heafner, J., et al. (2014). Moral 
judgment depends on language. PLoS One, 9, e94842.

Crepaldi, D., Keuleers, E., Mandera, P., \& Brysbaert, M. (2013). SUBTLEX-IT. Retrieved from http://crr.ugent.be/subtlex-it/

Dehaene, S., \& Cohen, L. (2011). The unique role of the visual word form area in reading. Trends in cognitive sciences, 15, 254-262.

Del Maschio, N., Sulpizio, S., Fedeli, D., Ramanujan, K., Ding, G., Weekes, B. S., ... \& Abutalebi, J. (2018). ACC Sulcal Patterns and Their Modulation on Cognitive Control Efficiency Across Lifespan: A Neuroanatomical Study on Bilinguals and Monolinguals. Cerebral Cortex, 1, 11.

Dhooge, E., \& Hartsuiker, R. J. (2011). How do speakers resist distraction? Evidence from a taboo picture-word interference task. Psychological Science, 22, 855-859.

Di Cesare, G., Marchi, M., Errante, A., Fasano, F., \& Rizzolatti, G. (2017). Mirroring the social aspects of speech and actions: the role of the insula. Cerebral Cortex, 28, 1348-1357.

Etkin, A., Egner, T., \& Kalisch, R. (2011). Emotional processing in anterior cingulate and medial prefrontal cortex. Trends in cognitive sciences, 15, 85-93.

Friston, K. J., Holmes, A. P., Worsley, K. J., Poline, J. P., Frith, C. D., \& Frackowiak, R. S. J. (1995). Statistical parametric maps in functional imaging: A general linear approach. Hum Brain Mapping. 2, 189-210.

Ferre, P., Garcia, T., Fraga, I., Sanchez-Casas, R., \& Molero, M. (2010). Memory for emotional words in bilinguals: do words have the same emotional intensity in the first and in the second language?. Cognition \& Emotion, 24, 760-785.

Geipel, J., Hadjichristidis, C., \& Surian, L. (2015). The foreign language effect on moral judgment: The role of emotions and norms. PloS one, 10, e0131529. 
Güroğlu, B., van den Bos, W., Rombouts, S. A., \& Crone, E. A. (2010). Unfair? It depends: neural correlates of fairness in social context. Social Cognitive and Affective Neuroscience, 5(4), 414-423.

Hamann, S., \& Mao, H. (2002). Positive and negative emotional verbal stimuli elicit activity in the left amygdala. Neuroreport, 13, 15-19.

Hayakawa, S., Costa, A., Foucart, A., \& Keysar, B. (2016). Using a foreign language changes our choices. Trends in Cognitive Science, 20, 791-793.

Hayakawa, S., Tannenbaum, D., Costa, A., Corey, J. D., \& Keysar, B. (2017). Thinking more or feeling less? Explaining the foreign-language effect on moral judgment. Psychological science, 28, 13871397.

Harris, C. L., Aycicegi, A., \& Gleason, J. B. (2003). Taboo words and reprimands elicit greater autonomic reactivity in a first language than in a second language. Applied Psycholinguistics, 24, 561-579.

Hebart, M. N., Görgen, K., \& Haynes, J. D. (2015). The Decoding Toolbox (TDT): a versatile software package for multivariate analyses of functional imaging data. Frontiers in neuroinformatics, 8, 88.

Hubers, F., Snijders, T. M., \& De Hoop, H. (2016). How the brain processes violations of the grammatical norm: An fMRI study. Brain and language, 163, 22-31.

Jay, T. (2009). The utility and ubiquity of taboo words. Perspectives on Psychological Science, 4, 153161.

Janschewitz, K. (2008). Taboo, emotionally valenced, and emotionally neutral word norms. Behavior Research Methods, 40, 1065-1074.

Kimura, M. (1990). Behaviorally contingent property of movement-related activity of the primate putamen. Journal of Neurophysiology, 63, 1277-1296. 
Keuleers, E., \& Brysbaert, M. (2010). Wuggy: A multilingual pseudoword generator. Behavior research methods, 42, 627-633.

LaBar, K. S., \& Phelps, E. A. (1998). Arousal-mediated memory consolidation: Role of the medial temporal lobe in humans. Psychological Science, 9, 490-493.

Ljung M. (2011) History of Swearing. In: Swearing. Palgrave Macmillan, London.

Mackay, D. G., Shafto, M., Taylor, J. K., Marian, D. E., Abrams, L., \& Dyer, J. R. (2004). Relations between emotion, memory, and attention: Evidence from taboo Stroop, lexical decision, and immediate memory tasks. Memory \& Cognition, 32, 474-488.

Martin, A., Schurz, M., Kronbichler, M., \& Richlan, F. (2015). Reading in the brain of children and adults: A meta-analysis of 40 functional magnetic resonance imaging studies. Human Brain Mapping, 36, 1963-1981.

Medler, D.A., \& Binder, J.R. (2005). MCWord: An On-Line Orthographic Database of the English Language. http://www.neuro.mcw.edu/moword/

Mehl, M. R., \& Pennebaker, J. W. (2003). The sounds of social life: A psychometric analysis of students' daily social environments and natural conversations. Journal of personality and social psychology, 84, 857-870.

Montefinese, M., Ambrosini, E., Fairfield, B., \& Mammarella, N. (2014). The adaptation of the affective norms for English words (ANEW) for Italian. Behavior Research Methods, 46, 887-903. Musz, E., \& Thompson-Schill, S. L. (2015). Semantic variability predicts neural variability of object concepts. Neuropsychologia, 76, 41-51.

Palomar-García, M. Á., Bueichekú, E., Ávila, C., Sanjuán, A., Strijkers, K., Ventura-Campos, N., \& Costa, A. (2015). Do bilinguals show neural differences with monolinguals when processing their native language?. Brain and language, 142, 36-44. 
Price, C. J. (2012). A review and synthesis of the first 20 years of PET and fMRI studies of heard speech, spoken language and reading. Neuroimage, 62, 816-847.

Rossi, E., Newman, S., Kroll, J. F., \& Diaz, M. T. (2018). Neural signatures of inhibitory control in bilingual spoken production. Cortex, 108, 50-66.

Rossell, S. L., Bullmore, E. T., Williams, S. C., \& David, A. S. (2001). Brain activation during automatic and controlled processing of semantic relations: a priming experiment using lexicaldecision. Neuropsychologia, 39, 1167-1176.

Singer, T., Kiebel, S. J., Winston, J. S., Dolan, R. J., \& Frith, C. D. (2004). Brain responses to the acquired moral status of faces. Neuron, 41, 653-662.

Stolier, R. M., \& Freeman, J. B. (2016). Neural pattern similarity reveals the inherent intersection of social categories. Nature Neuroscience, 19, 795.

Sulpizio, S., Vassallo, E., Job, R., \& Abutalebi, J. (2018). ITABÙ: Un database delle parole tabù per l'italiano [ITABÙ: An Italian database for taboo words]. Manuscript in preparation.

Taylor, J. S. H., Rastle, K., \& Davis, M. H. (2013). Can cognitive models explain brain activation during word and pseudoword reading? A meta-analysis of 36 neuroimaging studies. Psychological Bulletin, 139, 766-791.

Taylor, K. S., Seminowicz, D. A., \& Davis, K. D. (2009). Two systems of resting state connectivity between the insula and cingulate cortex. Human brain mapping, 30, 2731-2745.

Van de Putte, E., De Baene, W., Price, C. J., \& Duyck, W. (2018). Neural overlap of L1 and L2 semantic representations across visual and auditory modalities: a decoding approach. Neuropsychologia, 113, 68-77.

Van Heuven, W. J., Mandera, P., Keuleers, E., \& Brysbaert, M. (2014). SUBTLEX-UK: A new and improved word frequency database for British English. The Quarterly Journal of Experimental Psychology, 67, 1176-1190. 
Van Lancker, D., \& Cummings, J. L. (1999). Expletives: Neurolinguistic and neurobehavioral perspectives on swearing. Brain research reviews, 31, 83-104.

Van Overwalle, F. (2009). Social cognition and the brain: a meta-analysis. Human brain mapping, 30, $829-858$.

Viñas-Guasch, N., \& Wu, Y. J. (2017). The role of the putamen in language: a meta-analytic connectivity modeling study. Brain Structure and Function, 222, 3991-4004.

Wartenburger, I., Heekeren, H. R., Abutalebi, J., Cappa, S. F., Villringer, A., \& Perani, D. (2003). Early setting of grammatical processing in the bilingual brain. Neuron, 37, 159-170.

Zinchenko, O., \& Arsalidou, M. (2018). Brain responses to social norms: Meta-analyses of f MRI studies. Human brain mapping, 39, 955-970. 